\title{
Questes
}

\section{Figures royales à l'ombre du mythe : conclusion}

\section{Natalia Bercea-Bocskai et Amandine Mussou}

\section{(2) OpenEdition}

\section{Journals}

Édition électronique

URL : http://journals.openedition.org/questes/1544

DOI : 10.4000/questes. 1544

ISSN : 2109-9472

\section{Éditeur}

Les Amis de Questes

\section{Édition imprimée}

Date de publication : 15 janvier 2008

Pagination : 96-98

ISSN : 2102-7188

\section{Référence électronique}

Natalia Bercea-Bocskai et Amandine Mussou, « Figures royales à l'ombre du mythe : conclusion », Questes [En ligne], 13 | 2008, mis en ligne le 01 janvier 2014, consulté le 15 septembre 2020. URL http://journals.openedition.org/questes/1544 


\section{Conclusion}

\section{Natalia BERCEA-BoCSKAI et Amandine MUSSOU}

Les six études rassemblées ici ont tenté de confronter la royauté médiévale fictionnelle ou historique à un paradigme mythique qui s'impose dans un premier temps comme essentiellement normatif. Les communications se sont attachées aux différents visages que peut prendre cette confrontation au sein de textes narratifs composés entre le $\mathrm{XII}^{\mathrm{e}}$ et le $\mathrm{XV}^{\mathrm{e}}$ siècle et ont mis au jour les diverses stratégies qui président à la constitution de figures royales à l'ombre de mythes : évolution, omission, invention, sélection, adaptation, greffe sont autant d'opérations rendant compte de l'usage de modèles préexistants pour forger des images royales dans ces ouvrages.

L'analyse de la figure d'Uterpandragon qui investit certains récits étiologiques construits autour d'une «mauvaise coutume», ainsi que l'étude du mécanisme typologique relatif au paradigme du primus peccator (Sophie Albert) permettent au regard critique de scruter le noyau mythique de l'intérieur, révélant une poïétique complexe. C'est également sous l'angle du mythe en construction que la figure d'Arthur a été analysée : tout comme Uterpandragon, Arthur est un roi défaillant et ses faiblesses publiques (mélancoliques, amoureuses, politiques ou religieuses) forgent paradoxalement le mythe naissant (Pierre Levron). Remontant aux origines du monde arthurien, ces deux communications ont souligné le poids et la valeur symboliques de la faille dans la genèse du statut légendaire du roi.

La réflexion autour des enjeux mythiques de la royauté s'est ensuite organisée autour d'occurrences précises de reprises de cadres, séries ou 
séquences mythiques afin de les remodeler en fonction d'un projet auctorial, des attentes du public historique visé, des désirs du mécène ou des exigences idéologiques de la cour (Amandine Mussou, Sophie Poitral, Natalia BerceaBocskai, Anne Salamon). L'accent a été porté sur les effets de concordance et/ou de discordance engendrés par la valorisation de l'exemplum (Amandine Mussou, Natalia Bercea-Bocskai) ou la cumulation de figures exemplaires (Sophie Poitral, Anne Salamon) à l'usage des maisons royales du temps et d'une idéologie curiale. Ces études ont mis en évidence certaines stratégies de relecture de la mythologie à la lumière de l'actualité politique. Ainsi, ajouter un dixième personnage à la liste canonique des Neuf Preux afin de renforcer la gloire d'un lignage (Anne Salamon), utiliser à des fins politiques ou pour étayer des généalogies imaginaires des figures exemplaires éclectiques et parfois ambiguës comme le fait René d'Anjou dans Le Livre du Cuer d'Amour espris (Sophie Poitral), ou relire en clef à la fois apologétique et historique les exploits de Jason renvoyant symboliquement aux projets ambitieux de Philippe de Bourgogne (Natalia Bercea-Bocskai), sont autant de gestes qui corrigent et enrichissent de nouvelles significations le cadre mythique. Immixtion et distanciation caractérisent paradoxalement le rapport à l'imaginaire mythique, biblique et légendaire des ouvrages analysés.

Le personnage royal se construit certes à l'ombre, mais aussi à la lumière du mythe. L'ancrage mythique permet à la fois d'éclaircir son rôle et de légitimer son identité même, comme dans le cas de la reine Mirro, personnage positif par excellence, inventé et inséré dans le mythe de la Toison d'or afin de participer à la réhabilitation de Jason et de concurrencer Médée (Natalia BerceaBocskai). La référence mythique, qu'il soit question de modèles à suivre ou de contre-exemples à éviter, comme dans le cas de Moïse et d'Evilmerodag, comparants de Charles VI (Amandine Mussou), se mue en un miroir à l'usage du roi ou de la cour. Ce miroir édifiant et flatteur (dont la reine Mirro semble être, par son nom même, l'incarnation parfaite) est tendu par un auteur qui 
marque son texte, par le biais d'identifications révélatrices ou de gloses critiques, du sceau de ses propres prises de position (Amandine Mussou, Sophie Poitral, Natalia Bercea-Bocskai).

Ces réflexions en marge de la constitution ou de la réactualisation du mythe permettent d'envisager une remise en question du paradigme mythique en tant que norme ou prototype immuable. Les failles d'un mythe littéraire, telles celles incarnées par Uterpandragon et Arthur (Sophie Albert et Pierre Levron), l'ambiguïté, la fluctuation ou le caractère parfois subversif de la mise en série de héros légendaires comme dans le cas des Neuf Preux ou de l'inscription des héros sur le portail du cimetière du dieu d'Amour dans Le Livre du Cuer d'Amour espris de René d'Anjou (Anne Salamon, Sophie Poitral), la mise en regard inédite de deux modèles hétérogènes, comme les figures de Moïse et d'Evilmerodag (Amandine Mussou), ou encore l'insertion de nouvelles figures qui infléchissent le cadre mythique (Natalia Bercea-Bocskai) constituent autant de signes de sa perméabilité. De nouvelles mythologies prennent forme sous les yeux du lecteur, engageant la vérité mythique dans la recherche de vérité contemporaine, sociale ou politique. 